\title{
Explaining prosecution outcomes for cryptocurrency-based financial crimes
}

\begin{abstract}
Purpose: Cryptocurrencies have been used to commit various offences, but enforcement efforts remain underdeveloped relative to the value of these crimes. This paper examines factors associated with outcomes of U.S.-based cryptocurrency financial crime prosecutions. Design/methodology/approach: We studied the 37 resolved cryptocurrency-based financial crime cases in the U.S. to date, exploring the impact of offence, defendant, and evidence characteristics on the mode of disposition and penalties. We used bivariate analyses and logistic regression models to determine relationships among these variables.

Findings: The presence of individual defendants only (rather than a corporate defendant or combination thereof) and the use of only a cryptocurrency other than Bitcoin in committing a crime each made a case less likely to be resolved by dismissal, trial, or summary or default judgment.

Originality: This paper is the first to examine variables contributing to financial crime prosecution outcomes and has implications for prosecutorial decision-making, resource allocation, and the prevention and detection of financial offences involving cryptocurrencies.
\end{abstract}

Keywords: Bitcoin, cryptocurrencies, cryptoassets, financial crime, prosecution, virtual assets

\section{$1 \quad$ Introduction}

The rise in popularity of cryptocurrencies since Bitcoin's release in 2009 has transformed the perpetration of financial crime by facilitating lower-cost, pseudo-anonymous ${ }^{1}$, and irrevocable money movement with low barriers to entry (Brenig et al., 2015; Durrant and Natarajan, 2019; Kethineni and Cao, 2019). To date, cryptocurrencies have been used to commit offences including money laundering; hacks, theft, and malware; initial coin offering scams and Ponzi schemes; sanctions violations; tax evasion; market manipulation; and other fraud. Enforcement efforts have begun - primarily in the U.S. - but remain in their infancy, particularly relative to the estimated value of the crimes, which CipherTrace estimated as $\$ 4.4$ billion from the beginning through the third quarter of 2019 (CipherTrace, 2019). As of February 2019, there had only been 51 cases involving cryptocurrency brought in U.S. courts or contemporaneously being publicly investigated (Kethineni and Cao, 2019).

A first step to improving cryptocurrency-based financial crime prosecution efforts is determining which factors are associated with prosecution outcomes of the same, i.e., are there any characteristics of cases that make successful prosecution more likely? Since these have so far primarily occurred in the U.S., we study the U.S. population of cases. Both legal and extralegal factors play a role in successful prosecution of crimes (Danziger et al., 2011) and offence, defendant, and evidentiary characteristics have been shown to influence prosecution outcomes in U.S. cases (Cramer, 1999; Engen and Gainey, 2000; Reitler et al., 2013; Ulmer and Johnson, 2004). Using publicly available case documents, bivariate analyses, and logistic regressions, this paper explores several variables in the aforementioned categories - such as the number of charges, mode of disposition, and type of defendants-present in cryptocurrency-based financial crime cases to determine their power in explaining case outcomes. This study is the first to look at factors explaining prosecution outcomes in financial crime cases, let alone

\footnotetext{
${ }^{1}$ Cryptocurrencies are considered pseudo-anonymous due to the transparent nature of their transactions, despite not being explicitly connected with particular individuals/companies (Meiklejohn et al., 2016).
} 
cryptocurrency-based financial crime cases. We seek to understand, in broad terms, why cases are resolved how they are, to improve future prosecutions and resource allocation.

\section{Related work}

There is sparse literature regarding factors associated with prosecution outcomes for financial crime offences. We therefore look to literature on factors affecting prosecution outcomes in other areas of law.

Prosecution outcomes can be categorised in various ways, but generally refer to whether charges were fully prosecuted or dismissed, whether a felony/misdemeanour was convicted, and the defendant's sentence (Kingsnorth et al., 2001). We can consider the mode of disposition with further granularity, for example whether a case was resolved by guilty plea, whether it was dismissed or diverted, or whether the defendant was found guilty or innocent at trial (Henning and Feder, 2005).

Most of the empirical research on prosecution outcomes examines criminal cases generally (Engen and Gainey, 2000; Reitler et al., 2013; Ulmer and Johnson, 2004). One study explores felony drug prosecution decisions (Franklin, 2010) and others concern domestic and sexual violence cases (Cramer, 1999; K. Henning and Feder, 2005).

These studies' dependent variables include the mode of disposition of cases (Franklin, 2010; Henning and Feder, 2005), sentencing decisions (Engen and Gainey, 2000; Reitler et al., 2013; Ulmer and Johnson, 2004), and verdicts (Cramer, 1999). Independent variables generally fall under the following categories: defendant characteristics and case/offence characteristics. Defendant characteristics include defendant age, race, gender, income level, employment status, relationship to the victim, and prior criminal history. Case/legal characteristics include arrest characteristics, the nature of the offence, whether there was any injury to the victim, offence seriousness level/sentencing guidelines, the number of charges, and evidentiary characteristics (Cramer, 1999; Engen and Gainey, 2000; Franklin, 2010; Henning and Feder, 2005; Reitler et al., 2013; Ulmer and Johnson, 2004). Two studies (Cramer, 1999; Ulmer and Johnson, 2004) also include independent variables relating to more procedural factors, such as the time between the event and court action, who reported the crime, the judge, available jail space, trial rate, and court size and caseload.

Studies find that legal characteristics play a role in case outcomes (Engen and Gainey, 2000; Reitler et al., 2013). A defendant's criminal history is also significant (Cramer, 1999; Engen and Gainey, 2000; Henning and Feder, 2005; Reitler et al., 2013), as are extra-legal defendant characteristics (Cramer, 1999; Engen and Gainey, 2000; Reitler et al., 2013), but generally to a lesser extent (Engen and Gainey, 2000; Reitler et al., 2013). One study (Ulmer and Johnson, 2004) finds that the characteristics that pertain to the courts themselves (such as caseload pressure) have a significant impact on sentencing outcomes, both alone and when considered with defendant characteristics.

Finally, evidence is predictive of case outcomes. One study (Franklin, 2010) uses two proxies for the strength of evidence: initial case screening and same-day arrest. Cases that were initially screened are less likely to be dismissed than those that were not and cases where the defendant was arrested on the same day as the incident are also less likely to be dismissed (Franklin, 2010). This suggests that the strength of evidence has a direct effect on case outcomes. The existence of photographic evidence is also predictive of the verdict in a case. The presence of 
photographic evidence makes a case more likely to result in either a guilty verdict or a case being taken under advisement (Cramer, 1999). Another study (Smit et al., 2018) uses 'a systematic content analysis to identify misleading evidence' in Court of Appeals cases in England and Wales, looking at witness, forensic, and character evidence. In their set of cases, witness and forensic evidence are the two most common types of evidence deemed to be misleading by the Court of Appeals, suggesting that they played a meaningful role in the original outcome of the case (Smit et al., 2018).

\section{$3 \quad$ Method}

\subsection{Case selection}

We explore cases prosecuted in the U.S., as more cryptocurrency-based financial crimes have been prosecuted there than anywhere else. In a study of cases up to February 2019, Kethineni and Cao (2019) found that $41 \%$ of all cases brought involving cryptocurrencies were in U.S. courts (Kethineni and Cao, 2019).

We conducted a search on Westlaw, an online legal research database. Westlaw contains dockets from all U.S. federal court cases and all the documents filed therein. A court docket is a list of all documents filed throughout the life of a case and records key case events such as hearings. These documents include court transcripts, motions, memoranda of law, evidence, and other documents. We conducted a search of all U.S. federal cases for 'cryptocurrency', for 'Bitcoin', and for 'virtual currenc*'. We expected some overlap in these search results.

We collected all cases (civil and criminal) where the case had been decided before 1 May 2020, which involved a financial crime offence and in which a cryptocurrency featured. We included the following offences:

- Fraud: Securities fraud, mail or wire fraud, bank fraud, tax evasion.

- Bribery and corruption: Foreign Corrupt Practice Act, Travel Act, bribery of public officials and witnesses, bribery of state, local, or Native American tribal government.

- Insider dealing and market abuse: Insider dealing, insider dealing with respect to tender offers, market abuse.

- Money laundering, terrorist financing, and financial/trade sanctions: Domestic money laundering, international money laundering, transacting in proceeds of unspecified unlawful activity, Bank Secrecy Act, bulk cash smuggling, providing material support to terrorists, providing material support or resources to designated foreign terrorist organisations, breach of financial or trade sanctions.

- Antitrust violations: cartel behaviour as prohibited by the Sherman Act, Clayton Act, and Federal Trade Commission Act (Zornow et al., 2018).

Although civil and criminal cases differ in their standards of proof and general goal, we include both because they are likely to be broadly equivalent in the terms we examine in this study (Bornstein and Rajki, 1994). We did exclude in $\mathrm{rem}^{2}$ civil asset forfeiture cases from this study.

After obtaining the data, we cross-referenced the list with press releases from all U.S. enforcement agencies handling financial crime cases to ensure we captured the entire population:

2 In rem cases are against property rather than individuals or companies. 
- Department of Justice;

- Securities and Exchange Commission;

- Commodity Futures Trading Commission;

- Federal Trade Commission;

- Internal Revenue Service;

- United States Department of the Treasury; and

- Financial Industry Regulatory Authority.

We then cross-referenced our sample with cases studied in a paper which looked at all cryptocurrency cases globally up to February 2019 (Kethineni and Cao, 2019).

We added all cases that met our inclusion criteria from these sources which were not in our original data set, using dockets found in various legal databases (detailed below).

\subsection{Data extraction and coding framework}

Dockets were obtained through Westlaw, the U.S. government Public Access to Court Electronic Records (PACER) service, and Court Listener, a repository provided by the Free Law Project, a U.S.-registered non-profit organisation.

We developed a coding framework from related studies. This was used to derive variables corresponding to case outcomes - our dependent variable(s) - and the characteristics of those cases and the offences to which they corresponded.

Following the studies described above, we extracted variables based on defendant, case, and outcome characteristics (Henning and Feder, 2005). Though these papers involve other areas of law, studies have found that in, for example, sexual assault cases, decision-making is similar to that in other types of cases, particularly in terms of the influence of legal variables on decision-making (Beichner and Spohn, 2005). Furthermore, although civil and criminal enforcement efforts differ in their standards of proof and penalties, we include both in this study because they are likely to be broadly equivalent in the cases we examine here (Bornstein and Rajki, 1994).

In response to Reitler et al.'s (2013) criticisms, we place greater emphasis on legal characteristics than extra-legal factors. Because financial crime cases tend to be less emotional than, for example, domestic violence cases, we further expect these legal characteristics to be at the fore.

Studies show that defendant characteristics play a role in case outcomes (Cramer, 1999; Ulmer and Johnson, 2004). Most studies on prosecution outcomes include defendant characteristics like race, age, and income level, but we do not include those in our analysis because a) we expect them to be rather heterogenous, and b) the data are not readily available. Many cases we study are also unlikely to have a clear 'victim'.

Due to the inapplicability of age or race in this context, for defendant characteristics, we focus on the number of defendants (many scholars (such as Dawson (1979) have argued that joinders for criminal offences unfairly prejudice defendants) and whether defendants were corporations or individuals. The second variable did not arise in any studies reviewed. However, the U.S's policy of individual accountability for corporate crime (through the Yates Memo) (Henry, 
2016) implies that if a corporation accepts responsibility for actions by one of their employees, an individual subsequently charged with the same conduct should, intuitively, be more likely to be found guilty.

In terms of case characteristics, following Franklin (2010), we look at the number of charges filed (Franklin, 2010). Legal scholars (such as Zaytoun (2018)) have suggested that wire fraud would be useful to charge in cryptocurrency-based financial crime offences, so we also examine it as an independent variable (Zaytoun, 2018). Wire fraud is a broad offence encompassing fraud involving information and communication technology-based transmissions (which can be monetary, written, pictorial, or sonic) (18 U.S.C. $\S 1343$ ). The nature of cryptocurrencies means any fraud committed involving cryptocurrencies could fit this definition.

Following various studies on case outcomes, we extract the following variables: ruling (Cramer, 1999), whether a defendant was detained or released (Reitler et al., 2013; Ulmer and Johnson, 2004), and the mode of disposition (Henning and Feder, 2005). The literature reviewed did not examine monetary penalties as an independent variable (likely to be due to the nature of the crimes studied), but, in this work, we consider it a case 'outcome' as well. Following scholars who examine the impact of additional evidence on prosecution outcomes (Cramer, 1999; Franklin, 2010), we also extract evidentiary characteristics.

The coding scheme-including category definitions and sources of data - is summarised in Table I.

[Insert Table 1. Coding scheme]

If, for any variable, more than one code was applicable for a given case, the highest one was used. For example, if a case included a guilty plea by one defendant, and a default judgment for another, we coded it as 5 (for the guilty plea). If one defendant was charged with 6 counts in an indictment, and another with 11, we coded it as 3 . In the case of appeals, we used the ultimate outcome to code the case. So, if a sentence was vacated entirely on appeal, we coded it as a 'non-custodial' sentence, even if the defendant had served some of their original sentence. Time served counted as a custodial sentence.

Forensic evidence in these cases was primarily financial forensic evidence and included information on monetary flows or bank statements. Qualitative evidence included emails or text messages, screenshots of websites or advertisements, or photographic evidence. Finally, witness evidence could be 'live' trial witness testimony or from declarations or depositions, including from expert witnesses. Evidence categories refer to evidence filed by the plaintiff between the initial complaint/charging document and the judgment. This excludes evidence filed with any superseding complaints/indictments/information and post-judgment sentencing evidence. One case involved stipulations that certain forensic evidence, including bank statements, would be sealed: the existence of this sealing order implied the existence of such quantitative evidence so, even though we did not have access to it, we coded it as such.

We did not consider real property in assessing disgorgement and restitution.

\subsection{Inter-coder reliability}


Two additional coders with legal knowledge were provided with detailed and coded $20 \%$ of our sample. We then calculated the prevalence- and bias-adjusted Kappa statistic for all three coders to determine inter-coder reliability (Byrt et al., 1993).

\subsection{Analysis}

To understand how our independent variables were associated with case outcomes, we used bivariate analyses (Henning and Feder, 2005). In addition to associations, we were interested in the predictive value of case, evidentiary, and defendant characteristics in relation to case outcomes; we explored this using logistic regressions due to the categorical nature of our dependent variables. We conducted logistic regressions for different aggregations of our variables, using $\mathrm{p}<.05$ as our decision threshold and odds ratios for our effect sizes.

\section{$4 \quad$ Results and analysis}

\subsection{Final data set}

Our initial searches revealed 483 cases; however, this included many duplicates and cases which did not meet the inclusion criteria for our study. Using Westlaw summaries and press releases, we removed duplicates, cases that did not involve a financial crime offence, in rem cases, cases where a decision had not been reached by 1 May 2020, cases where too many documents were sealed, cases not involving a government plaintiff, and cases on appeal. This resulted in the removal of 404 cases.

After cross-referencing with Kethineni and Cao's (2019) paper and U.S. government enforcement agency press releases, we were left with an initial set of 50 cases, which we used as our sample to examine inter-coder reliability.

After conducting more detailed data extraction and excluding other cases which had not yet been resolved, we arrived at a final set of 37 cases. $^{3}$ While small in comparison to previous studies, this constitutes the entire universe of cases which met the search criteria. Ten of these cases came from U.S. government press releases, eight from Kethineni and Cao's (2019) paper, and 18 from our original Westlaw search. The final case was a criminal case parallel to one from our original search, brought to our attention in reviewing the case documents for the civil case.

\subsection{Inter-coder reliability}

Two individuals with prior legal knowledge each coded the same subset of 10 cases, randomly selected from our population. We provided them with instructions (including narrative instructions and a flow chart) and the relevant legal documents. This resulted in a Kappa of 0.79 , significant at a .0001 level, indicating a high level of agreement among the three coders. Thus, for the full sample, we used the author's coding.

\subsection{Frequencies and descriptive results}

Table II shows the coding frequencies for all cases and percentages for all cases.

\footnotetext{
${ }^{3}$ Our full dataset can be found here: https://osf.io/wfy5m/?view only=573ba82c86b04a2c8c6ab13d897428b1.
} 
Figure 1 provides a graphical representation of the above frequency table.

[Insert Figure 1. All case results]

Of the criminal cases in our data set, $83 \%$ were resolved by guilty plea, and $89 \%$ of defendants received a custodial sentence. Of the civil cases, $47 \%$ settled, and $42 \%$ were resolved by default or summary judgment. Very few of the cases went to trial $(11 \%$, with only $8 \%$ going through a jury trial).

For the civil cases studied, $84 \%$ had two through five counts charged. For criminal cases, the same range of charges was most common, but the maximum number of charges was much larger than for civil cases.

Charges in our data set included different types of fraud, failure to register (either securities, exchanges, as a broker-dealer, or money transmitting businesses); off-exchange transactions; wire fraud; money laundering; reporting violations; market manipulation; obstruction of justice; and aiding and abetting and conspiracy violations thereof. To a lesser extent, charges involved narcotics and firearm violations; computer hacking; extortion; and tax violations. Surprisingly, wire fraud was only charged in $22 \%$ of the criminal cases.

Almost all cases reviewed included Bitcoin in some capacity (70\%). However, this was more evenly split for civil cases than criminal cases (in civil cases, $47 \%$ used only another cryptocurrency and 53\% used Bitcoin).

In terms of extra-legal defendant characteristics, in the criminal cases studied, $61 \%$ had only one defendant, and $94 \%$ had only individual defendants. Comparatively, $79 \%$ of civil cases had two, three, four, or five defendants, and $80 \%$ included a corporate defendant.

Qualitative evidence only was much more frequently used as proof than quantitative evidence $(65 \%$ versus $35 \%)$. Furthermore, the quantitative evidence we saw in our data set was relatively basic, usually only being bank statements rather than analytical flows or statistical evidence. Additional evidence was filed in $51 \%$ of cases and witness evidence was present in $60 \%$ of cases.

\subsection{Analysis}

Having explored the general characteristics of the cases, we performed analyses to test for statistical relationships. We first used contingency tables to examine associations among our variables and then built models to determine the nature and direction of these relationships.

\subsubsection{Bivariate analyses}

For our entire population, the most common number of counts charged was two to five $(65 \%)$. These cases were most often resolved by settlement (38\%), followed by guilty pleas (33\%) and summary or default judgment (29\%). This trend is the same for civil cases only, except for cases being resolved by guilty plea (which would not apply); $56 \%$ were resolved by settlement and $44 \%$ were resolved by summary or default judgment. Cases involving two to five defendants (the most common number of defendants) followed the same trend, with $36 \%$ being 
disposed by settlement, $27 \%$ by guilty plea, and $23 \%$ by summary or default judgment (though the other cases with two to five defendants were resolved by other means).

Cases involving Bitcoin (70\%) were more often resolved by guilty plea (50\%) than any other mode of disposition. Cases involving an individual defendant only (rather than a corporate one) were most often resolved by guilty plea (74\%) and cases with a corporate defendant were most often resolved by settlement (44\%) or summary or default judgment (39\%).

For criminal cases, all cases that did not have any witness evidence or forensic evidence were resolved by guilty plea. Those with witness evidence or forensic evidence were disposed by guilty plea $50 \%$ of the time and by jury trial $50 \%$ of the time.

\subsubsection{Logistic regressions}

Following prior research (Franklin, 2010; Henning and Feder, 2005; Reitler et al., 2013), we used logistic regression to determine the nature and direction of relationships among our variables, while accounting for simultaneous effects. All variables introduced in the previous section were included as independent variables to examine their influence on case outcomes. However, due to the existence of perfect collinearity between witness evidence and forensic evidence, we excluded witness evidence from our models.

Using the original coding scheme, the effects of the number of charges, cryptocurrency used, number of defendants, type of defendants, type of forensic evidence, and presence of additional evidence on the disposition of all cases were not significant predictors of disposition. The results of this model were also unstable, seemingly due to the relatively low number of cases in various categories (and a resulting failure to converge) and zero counts for some variable combinations. We therefore built an alternative version of the model by aggregating categories of both independent and dependent variables.

The final model is a binomial logistic regression in which the dependent variable, disposition, has two levels: a case being resolved by guilty plea or settlement, or it being disposed by other means. We ultimately aggregated these variables because we analysed civil and criminal cases together; a settlement was the nearest equivalent in a civil case to a guilty plea in a criminal case (though we acknowledge that, in these civil settlements, defendants tended not to officially admit culpability). In this model, we also aggregated the number of defendants into two categories: solo defendants and multiple defendants. The full results of the logistic regression can be found in Table III.

When controlling for other variables, the type of cryptocurrency used and the type of defendant were significant predictors of disposition. The use of cryptocurrencies other than Bitcoin only in a case showed a significant association with cases being resolved by a means other than guilty plea or settlement. This corresponds to a multiplicative change in the odds of a case being resolved by some mode other than guilty plea or settlement by a factor of 0.02 . That is, when Bitcoin was not used in the case, the odds of a case being resolved by dismissal, trial, or summary or default judgment (relative to a guilty plea or settlement) decrease by $98 \%$.

The presence of an individual (rather than corporate) defendant showed a significant association with cases being resolved by a means other than guilty plea or settlement as well. This corresponds with a multiplicative change in the odds of the case being resolved by a means other than guilty plea or settlement by a factor of 0.014 . Accordingly, when there is only an 
individual defendant (or defendants), the odds of a case being resolved by dismissal, trial, or summary or default judgment (relative to a guilty plea or settlement) decrease by $98.6 \%$.

The other independent variables included in this model were not significant predictors of the mode of disposition.

[Insert Table III. Effect of independent variables on disposition: aggregated disposition (resolved by guilty plea or settlement or resolved by other means) and number of defendants (one or more than one)]

These results are consistent with analysis of the contingency tables. $79 \%$ of cases with only individual defendants (rather than corporate) were resolved by guilty plea or settlement (though we note that, of those, only a single case was resolved by settlement). Of the cases where only cryptocurrencies other than Bitcoin (or unspecified cryptocurrencies) were involved, $82 \%$ were resolved by guilty plea or settlement (though, of the cases resolved by guilty plea or settlement, $78 \%$ were resolved by settlement).

\section{Discussion}

This paper examined the factors associated with outcomes of U.S.-based cryptocurrency financial crime prosecution, specifically looking at the influence offence, defendant, and evidentiary characteristics on the mode of disposition of cases. When controlling for other independent variables, the presence of individual (rather corporate) defendants or the use of only cryptocurrencies other than Bitcoin each made a case less likely to be resolved by dismissal, trial, summary or default judgment. This study was the first to examine variables contributing to financial crime prosecution outcomes and has implications for prosecutorial decision-making, resource allocation, and the prevention and detection of financial offences involving cryptocurrencies.

\subsection{Discussion of individual variables}

\subsubsection{Disposition}

Our finding that $83 \%$ of the criminal cases were resolved by guilty plea is consistent with research that $97 \%$ of criminal convictions in the U.S. are obtained by guilty plea (Dervan, 2012). All but one case (a civil case) was disposed in favour of the government plaintiff, which supports previous findings that the government tends to prevail in prosecutions (Eisenberg, 1989). We note that resource limitations (on the part of both defendants and the government) may also be the cause of the high number of guilty pleas (Ross, 2006). Particularly as this is a new area of prosecution, prosecutors have a greater incentive to decrease the risk of losing a case and to resolve cases efficiently to develop favourable precedent.

\subsubsection{Charges}

Overcharging and sentencing guidelines create incentives for defendants to plead guilty (Dervan, 2012; Ross, 2006). Given that only 14\% of all cases charged a single count, overcharging appears to be one tactic prosecutors use to secure victories in cryptocurrencybased financial crime cases, though we did not quantify this effect. Many cases charged several counts of money laundering, for example, for similar conduct, alongside conspiracy to commit 
money laundering. In other cases, prosecutors charged an offence and 'aiding and abetting' the same offence separately where there was more than one defendant. Three of the cases charged 11 or more counts and many criminal cases involved superseding indictments with further charges, which were later resolved by guilty plea. These may be examples of horizontal overcharging (Caldwell, 2011). Our results further showed that, in many cases where several charges were filed, the prosecutors dismissed all but one count in exchange for a guilty plea, further suggesting possible overcharging.

Our bivariate analyses also support this assertion. The most common number of counts charged was two to five; these cases were then most often resolved by settlement or guilty plea, followed by summary or default judgment. None of the cases with two to five counts charged went to trial. In these cases, facing numerous charges may have motivated defendants to resolve their cases through settlement or guilty plea or, in more dramatic cases, attempting to avoid facing them entirely (leading to summary or default judgments).

Prosecutors must only show probable cause for a charge, not have all the evidence required to prove it beyond a reasonable doubt then and there. Though we did not quantify this effect, these preliminary observations suggest future research on the strength of evidence and overcharging in cryptocurrency-based financial crime cases may be pertinent.

While we expected many charges observed such as failure to register and money laundering, wire fraud was charged much less commonly (only $22 \%$ of criminal cases) than anticipated. We also saw no Foreign Corrupt Practices Act (FCPA) or sanctions violations charges, which was surprising, particularly given other researchers' suggestions these crimes are occurring (Rohlfsen et al., 2018; U.S. Department of the Treasury, n.d.). Considering the media's suggestion of the prevalence of narcotics crimes involving cryptocurrencies (and cryptocurrencies' use in laundering the proceeds of such crimes), narcotics charges were rather rarer than expected. However, some cases involving such crimes with many defendants were ongoing (and had been for several years) so these cases may just take longer to be resolved. Only one case charged tax violations involving cryptocurrencies, which is surprising considering the U.S.'s generous estimate of the value of these crimes in reality ( $\$ 40-70$ billion per year) (Jafari et al., 2018). It is possible that the magnitude of these crimes is overestimated, or that they are more difficult to identify, investigate, or successfully prosecute.

\subsubsection{Cryptocurrency}

Most cases reviewed involved Bitcoin in some capacity (70\%). Somewhat surprisingly, almost no cases involved historically popular cryptocurrencies such as Litecoin or Ripple. Previous research (Kethineni and Cao, 2019) indicated that most crimes involve Bitcoin versus other cryptocurrencies, but it is unclear if criminals who use Bitcoin who are merely most commonly caught by authorities.

Our logistic regression models also showed cases that did not involve Bitcoin at all were less likely to be resolved by dismissal, trial, or summary or default judgment (in fact, none were dismissed or resolved by trial, and only two cases $(18 \%)$ were resolved by summary or default judgment). This is perhaps because many of the cases that did not involve Bitcoin were unsophisticated ICO scams - a defendant would be unlikely to see a case through to trial which, based on the evidence presented, they had little chance of winning. Such an unsophisticated criminal may also be less capable evading the charges altogether (resulting in summary or default judgment). Most of these cases ultimately settled. 


\subsubsection{Defendants}

The results of our study are consistent with prior research that the existence of co-defendants did not impact the chances of conviction (Leipold and Abbasi, 2006). Despite these aggregate results, intuitively, on a case level, there could be an impact. For example, if one defendant pleads guilty to conduct alleged to be committed with his/her co-defendant, this may serve as evidence against them, naturally increasing the chances of conviction. No cases in our population involving two to five defendants went to trial but were slightly more often resolved by settlement than guilty plea or summary judgement. There might have been pressure for another defendant to plead guilty once their co-defendant had done so, though we do not quantify this effect.

We found that the presence of an individual (rather than a corporate) defendant only made a case less likely to be resolved by dismissal, trial, or summary or default judgment. Individual defendants may have less resources than a company to fight a case through trial. It is likely harder for individuals to avoid facing their charges (resulting in summary or default judgment) without the added layer of the corporate veil to shield them from the law. In some cases, the individual running the company appeared to face his/her charges but avoided doing so on behalf of his/her company.

Bivariate analyses also revealed that individual defendants most often pled guilty. Given the dominant paradigm of individual liability for financial crimes as per the Yates Memo, it makes sense that prosecutors would seek to charge individuals where they had a particularly strong case, which would lead to a guilty plea.

Furthermore, contrary to our expectation that primarily legal factors would play a predictive role in our population of cases (and previous research finding the same (Engen and Gainey, 2000; Reitler et al., 2013), it was, in the end, also an extra-legal factor (a defendant characteristic) that explained case outcomes (when controlling for legal factors, so they clearly remain important as well).

\subsubsection{Evidence}

The quantitative evidence we saw in our data set was notably basic, usually only consisting of bank statements rather than blockchain flows or statistical evidence. However, increasingly, in private cases, parties are employing the likes of Chainalysis to conduct investigations (Crump, 2019).

In two recent Chinese cases, courts 'confirmed for the first time that electronic data stored on or generated by blockchain met the requirements of authenticity and integrity and proposed a specific procedural test to identify blockchain evidence' (Wu and Zheng, 2020). There is ongoing debate about its admissibility in U.S. courts. Some scholars consider this (and the Blockchain Enabling Act in Vermont) to be 'overinclusive', and the U.S. Federal Rules of Evidence to be 'underinclusive' in that one could argue that blockchain evidence is inadmissible as hearsay (Guo, 2016; Marchant, 2019; Spring, 2019). If courts consider blockchain evidence as computer-generated it may not be hearsay, as in United States $v$. Lizzaraga-Tirado (which dealt with Google Earth evidence). However, courts could find it is human generated since it is created by individuals conducting transactions. The 'consensus algorithm' may negate this argument and challenge concerns about authenticity. Blockchain 
evidence could also be admissible under the Business Records Exception of the Federal Rules of Evidence (Guo, 2016). Another issue is that most judges are simply not familiar with the mechanisms of blockchain (Marchant, 2019). It is unclear whether this type of evidence was not included in these prosecutions because prosecutors thought it might be deemed inadmissible, because they were not confident in their own, the judge's, or the jury's understanding of the technical intricacies of the blockchain, or because it was simply unnecessary because prosecutors chose cases that did not require such complex evidence to prove.

In $60 \%$ of the cases studies, there was some form of witness evidence presented. All cases without witness evidence were resolved by guilty plea. Due to the collinearity of these results with our data on other evidence, we did not explore this further. However, this association supports previous findings about the importance of credible witness testimony in successful prosecutions (Albonetti, 1986). Expert witness evidence could also prove particularly important in validating blockchain evidence (Guo, 2016).

Additional evidence was only filed in $51 \%$ of cases. This could be because there was simply no need-prosecutors had a nearly unbeatable case from the beginning. However, this could also be related to overcharging. Prosecutors may not have had the additional evidence and simply charged extra counts to secure a guilty plea. Because of the lack of evidence, it is unclear if the defendants were actually guilty in all of the cases resolved by guilty plea or if it was simply too big of a risk for them to exercise their right to trial by jury. Given that, in one study, more than half of innocent defendants pleaded guilty, it is reasonable to suspect the same could be happening here (Dervan, 2012). Furthermore, our results differ from previous research showing evidence is predictive of case outcomes (Cramer, 1999; Franklin, 2010).

\subsection{Limitations}

This research was limited by the small population of cases which fit the search criteria, limiting the extent to which inferential statistical analysis could be performed. This is because the field is relatively new and some of the first prosecutions in this area are still ongoing (many prosecutions last several years). The novel nature of these crimes also means that norms in treatment may not have yet been firmly established; this could account for the low levels of predictability among variables. The population size was further limited by the coronavirus pandemic, which meant that many cases which would have been resolved by 1 May 2020 were delayed, as did the need to exclude some cases where too many documents were sealed. Due to the small population size, in many cases, this research analysed civil and criminal cases together. However, ultimately, the relatively small population of cases did allow a useful predictive model to be built which addressed the research question posed and can guide future research.

So far, these cases have mostly been prosecuted in the U.S., which limits the applicability of the results to other jurisdictional contexts. The nature of the U.S. legal system also meant that all but one of the cases were either settled or disposed in favour of the government plaintiff, which could create a bias in the data and, again, limit the results' global applicability. Finally, all cases were treated the same, despite their home in varying courts, when other scholars (Langer, 2005) have found disparities in treatment of cases across the country.

Due to the small population, very basic data were extracted from the cases, which could be seen as an oversimplification. For example, the coding process did not distinguish between 
expert and fact witness testimony of cases. Furthermore, some potentially useful other variables, such as monetary penalties for criminal cases, were excluded (in this case, due to the parallel in rem civil asset forfeiture cases). However, the aim of this research was merely to obtain a baseline of influential factors.

\section{$5.3 \quad$ Future research}

Future research could explore the variables studied here with more granularity. For example, researchers could look at combinations of specific charges or the burden of proof for those charges. Further research could also examine factors which may influence outcomes which were not explored in this study, such as the quality and type of counsel (Eisenberg, 1989; Erez and Tontodonato, 1990), victim participation (Belknap and Graham, 2000; Erez and Tontodonato, 1990), prior criminal record (in our study, only one defendant had one), and defendant income.

Given the relatively small number of cases in the population, future research could expand the search criteria to include all financial crime cases. This data could be used to train models which could be tested on cryptocurrency cases. We could also expand the search to cases which do not involve a government plaintiff. Additionally, it may be useful to conduct further analysis once the field is more mature and a larger body of cases exists.

\section{Conclusions}

Ultimately, defendant and factual characteristics were statistically significant predictors of outcomes in cryptocurrency-based financial offence prosecutions, when controlling for other legal and evidentiary variables and defendant characteristics. This is consistent with previous research in other areas of law finding that offence and defendant characteristics play a role in case outcomes. Notably, rather than the demographic defendant characteristics shown to influence case outcomes in other areas of law, this study found the type of defendant to be a significant predictor of case outcomes. Furthermore, the offence characteristic which proved significant was related to the facts of the case, rather than specifically 'legal' characteristics, like the number of charges or specific charges alleged.

Though the small population size somewhat limited quantitative analysis thereof, it also facilitated more granular analysis at the case level of variables associated with case outcomes in this field. For example, the universe of cases may provide insight into U.S. prosecutors' charging decisions in these cases; though we cannot quantify the effect, it appears that overcharging may be being used to secure guilty pleas and that prosecutors are only choosing to pursue unbeatable cases (potentially to develop strong precedent in this area or due to resource limitations). This is further supported by the limited amount and sophistication of evidence filed. Further research is needed into the role of blockchain evidence in cryptocurrency-based financial crime prosecutions, particularly as this area of law matures. 


\section{References}

Albonetti, C.A., 1986. Criminality, Prosecutorial Screening, and Uncertainty: toward a Theory of Discretionary Decision Making in Felony Case Processings. Criminology $24,623-644$.

Beichner, D., Spohn, C., 2005. Prosecutorial Charging Decisions in Sexual Assault Cases: Examining the Impact of a Specialized Prosecution Unit. Criminal Justice Policy Review 16, 461-498. https://doi.org/10.1177/0887403405277195

Belknap, J., Graham, D.L.R., 2000. Factors Related to Domestic Violence Court Dispositions in a Large Urban Area: The Role of Victim/Witness Reluctance and Other Variables, Final Report (No. 184232). U.S. Department of Justice.

Bornstein, B.H., Rajki, M., 1994. Extra-legal factors and product liability: The influence of mock jurors' demographic characteristics and intuitions about the cause of an injury. Behavioral Sciences \& the Law 12, 127-147. https://doi.org/10.1002/bsl.2370120204

Brenig, C., Accorsi, R., Müller, G., 2015. Economic Analysis of Cryptocurrency Backed Money Laundering, in: ECIS. https://doi.org/10.18151/7217279

Brown, J.M., Hamilton, C., O’Neill, D., 2007. Characteristics associated with rape attrition and the role played by scepticism or legal rationality by investigators and prosecutors. Psychology, Crime \& Law 13, 355-370. https://doi.org/10.1080/10683160601060507

Byrt, T., Bishop, J., Carlin, J.B., 1993. Bias, prevalence and kappa. J Clin Epidemiol 46, 423-429. https://doi.org/10.1016/0895-4356(93)90018-v

Caldwell, H.M., 2011. Coercive Plea Bargaining: The Unrecognized Scourge of the Justice System. Cath. U. L. Rev. 61, 63-96.

CipherTrace, 2019. Cryptocurrency Anti-Money Laundering Report, 2019 Q3.

Communications Act Amendments, 1952, 2008, United States Code.

Cramer, E.P., 1999. Variables That Predict Verdicts in Domestic Violence Cases. J Interpers Violence 14, 1137-1150. https://doi.org/10.1177/088626099014011002

Crump, R., 2019. UK Moves Toward Treating Bitcoin As Property In Key Ruling - Law360 [WWW Document]. URL https://www.law360.com/articles/1193774/uk-movestoward-treating-bitcoin-as-property-in-key-ruling (accessed 6.19.20).

Danziger, S., Levav, J., Avnaim-Pesso, L., 2011. Extraneous factors in judicial decisions. Proc Natl Acad Sci U S A 108, 6889-6892. https://doi.org/10.1073/pnas.1018033108

Dawson, R.O., 1979. Joint Trials of Defendants in Criminal Cases: An Analysis of Efficiencies and Prejudices. Michigan Law Review 77, 1379-1455. https://doi.org/10.2307/1288108

Dervan, L., 2012. White Collar Overcriminalization: Deterrence, Plea Bargaining, and the Loss of Innocence. Ky. L.J. 101, 723-752. 
Durrant, S., Natarajan, M., 2019. Cryptocurrencies and Money Laundering Opportunities, in: Natarajan, M. (Ed.), International and Transnational Crime and Justice. Cambridge University Press, pp. 73-79. https://doi.org/10.1017/9781108597296.012

Eisenberg, T., 1989. Litigation Models and Trial Outcomes in Civil Rights and Prisoner Cases. THE GEORGETOWN LAW JOURNAL 77, 37.

Engen, R.L., Gainey, R.R., 2000. Modeling the Effects of Legally Relevant and Extralegal Factors Under Sentencing Guidelines: The Rules Have Changed*. Criminology 38, 1207-1230. https://doi.org/10.1111/j.1745-9125.2000.tb01419.x

Erez, E., Tontodonato, P., 1990. The Effect of Victim Participation in Sentencing on Sentence Outcome *. Criminology 28, 451-474. https://doi.org/10.1111/j.17459125.1990.tb01334.x

Franklin, T.W., 2010. The intersection of defendants' race, gender, and age in prosecutorial decision making. Journal of Criminal Justice 38, 185-192. https://doi.org/10.1016/j.jcrimjus.2009.12.001

Guo, A., 2016. Blockchain Receipts: Patentability and Admissibility in Court. Chi.-Kent J. Intell. Prop. 16, 440-452.

Henning, K., Feder, L., 2005. Criminal Prosecution of Domestic Violence Offenses: An Investigation of Factors Predictive of Court Outcomes. Criminal Justice and Behavior 32, 612-642. https://doi.org/10.1177/0093854805279945

Henry, P.C., 2016. Individual Accountability for Corporate Crimes after the Yates Memo: Deferred Prosecution Agreements \& Criminal Justice Reform Notes. Am. U. Bus. L. Rev. 6, [i]-172.

Hirschel, D., Hutchinson, I.W., 2001. The Relative Effects of Offense, Offender, and Victim Variables on the Decision to Prosecute Domestic Violence Cases. Violence Against Women 7, 46-59. https://doi.org/10.1177/10778010122182299

Jafari, S., Vo-Huu, T., Jabiyev, B., Mera, A., Mirzazade farkhani, R., 2018. Cryptocurrency: A Challenge to Legal System. SSRN Journal. https://doi.org/10.2139/ssrn.3172489

Kethineni, S., Cao, Y., 2019. The Rise in Popularity of Cryptocurrency and Associated Criminal Activity. International Criminal Justice Review 1057567719827051. https://doi.org/10.1177/1057567719827051

Kingsnorth, R.F., MacIntosh, R.C., Berdahl, T., Blades, C., Rossi, S., 2001. Domestic Violence: The Role of Interracial/Ethnic Dyads in Criminal Court Processing. Journal of Contemporary Criminal Justice 17, 123-141. https://doi.org/10.1177/1043986201017002004

Langer, M., 2005. Rethinking Plea Bargaining: The Practice and Reform of Prosecutorial Adjudication in American Criminal Procedure. Am. J. Crim. L. 33, 223-300. 
Leipold, A.D., Abbasi, H.A., 2006. The Impact of Joinder and Severance on Federal Criminal Cases: An Empirical Study. Vand. L. Rev. 59, 347-404.

Marchant, G.E., 2019. Emerging Technologies and the Courts. Ct. Rev. 55, 146-153.

Meiklejohn, S., Pomarole, M., Jordan, G., Levchenko, K., McCoy, D., Voelker, G.M., Savage, S., 2016. A fistful of Bitcoins: characterizing payments among men with no names. Commun. ACM 59, 86-93. https://doi.org/10.1145/2896384

Messing, J.T., 2014. Evidence-Based Prosecution of Intimate Partner Violence in the PostCrawford Era: A Single-City Study of the Factors Leading to Prosecution. Crime \& Delinquency 60, 238-260. https://doi.org/10.1177/0011128710362056

O’Neal, E.N., Tellis, K., Spohn, C., 2015. Prosecuting Intimate Partner Sexual Assault: Legal and Extra-Legal Factors That Influence Charging Decisions. Violence Against Women 21, 1237-1258. https://doi.org/10.1177/1077801215591630

Reitler, A.K., Sullivan, C.J., Frank, J., 2013. The Effects of Legal and Extralegal Factors on Detention Decisions in US District Courts. Justice Quarterly 30, 340-368. https://doi.org/10.1080/07418825.2012.668925

Ross, J.E., 2006. The Entrenched Position of Plea Bargaining in United States Legal Practice Section V: Criminal Law and Procedure. Am. J. Comp. L. 54, 717-732.

Ryan Rohlfsen, Brendan Hanifin, Patrick Reinikainen, Ethan Thomas, 2018. Cryptocurrency Brings Rising International Risks [WWW Document]. Ropes \& Gray. URL http://www.ropesgray.com/en/newsroom/alerts/2018/05/the-international-risksassociated-with-digital-currency (accessed 12.14.19).

Smit, N.M., Morgan, R.M., Lagnado, D.A., 2018. A systematic analysis of misleading evidence in unsafe rulings in England and Wales. Science \& Justice 58, 128-137. https://doi.org/10.1016/j.scijus.2017.09.005

Spring, J.C., 2019. The Blockchain Paradox: Almost Always Reliable, Almost Never Admissible Comments. S.M.U. L. Rev. 72, 925-952.

Ulmer, J.T., Johnson, B., 2004. Sentencing in Context: A Multilevel Analysis. Criminology; Columbus 42, 137-177.

U.S. Department of the Treasury, n.d. OFAC FAQs: Sanctions Compliance [WWW Document]. U.S. DEPARTMENT OF THE TREASURY. URL https://www.treasury.gov/resource-center/faqs/Sanctions/Pages/faq_compliance.aspx (accessed 12.1.19).

Worrall, J.L., Ross, J.W., McCord, E.S., 2006. Modeling Prosecutors' Charging Decisions in Domestic Violence Cases. Crime \& Delinquency 52, 472-503. https://doi.org/10.1177/0011128705282496 
Wu, H., Zheng, G., 2020. Electronic evidence in the blockchain era: New rules on authenticity and integrity. Computer Law \& Security Review 36, 105401. https://doi.org/10.1016/j.clsr.2020.105401

Zaytoun, H.S., 2018. Cyber Pickpockets: Blockchain, Cryptocurrency, and the Law of Theft Comments. N.C. L. Rev. 97, 395-431.

Zornow, D., Strauber, J., Merzel, D., 2018. Financial crime in the United States: overview. 
Table I. Coding scheme

\begin{tabular}{|c|c|c|}
\hline Variable & Code & Source \\
\hline \multicolumn{3}{|l|}{ Dependent } \\
\hline Disposition & $\begin{array}{l}0=\text { Voluntary dismissal } \\
1=\text { Settlement without admitting to or } \\
\text { denying allegations } \\
2=\text { Jury trial } \\
3=\text { Bench trial } \\
4=\text { Default or summary judgment, trial } \\
\text { in absentia } \\
5=\text { Guilty plea }\end{array}$ & Docket \\
\hline $\begin{array}{l}\text { Sentence (criminal } \\
\text { cases) }\end{array}$ & $\begin{array}{l}0=\text { Non-custodial } \\
1=\text { Custodial }\end{array}$ & $\begin{array}{l}\text { Judgment, sentencing } \\
\text { order }\end{array}$ \\
\hline $\begin{array}{l}\text { Monetary penalty } \\
\text { (civil cases) }\end{array}$ & $\begin{array}{l}0=\text { Not alleged in complaint } \\
1=\text { Restitution }+ \text { disgorgement is less } \\
\text { than alleged in complaint (excluding } \\
\text { interest) } \\
2=\text { Restitution }+ \text { disgorgement is equal } \\
\text { to amount alleged in complaint } \\
\text { (excluding interest) } \\
3=\text { Restitution }+ \text { disgorgement is } \\
\text { greater than amount alleged in } \\
\text { complaint (excluding interest) }\end{array}$ & $\begin{array}{l}\text { Judgment, forfeiture order, } \\
\text { restitution order }\end{array}$ \\
\hline
\end{tabular}

\section{Independent \\ Offence \\ characteristics}

\begin{tabular}{lll}
\hline Charges & $\begin{array}{l}0=\text { One count } \\
1=\text { Two to five counts }\end{array}$ & $\begin{array}{l}\text { Complaint, indictment, } \\
\text { information }\end{array}$ \\
& $\begin{array}{l}\text { 2=Six to ten counts } \\
3=\text { Eleven or more counts }\end{array}$ & \\
\hline $\begin{array}{l}\text { Wire fraud charged } ? \\
\text { (criminal cases) }\end{array}$ & $\begin{array}{l}0=\text { Wire fraud not charged } \\
1=\text { Wire fraud charged }\end{array}$ & $\begin{array}{l}\text { Complaint, indictment, } \\
\text { information }\end{array}$ \\
\hline $\begin{array}{l}\text { Cryptocurrency } \\
\text { involved }\end{array}$ & $\begin{array}{l}0=\text { Other coin only or unspecified } \\
1=\text { Bitcoin involved }\end{array}$ & $\begin{array}{l}\text { Complaint, indictment, } \\
\text { information }\end{array}$ \\
\hline
\end{tabular}

Defendant

characteristics

\begin{tabular}{lll}
$\begin{array}{l}\text { Number of } \\
\text { defendants }\end{array}$ & $\begin{array}{l}0=\text { One defendant } \\
1=\text { Two to five defendants } \\
2=\text { Six or more }\end{array}$ & $\begin{array}{l}\text { Complaint, indictment, } \\
\text { information }\end{array}$ \\
\hline $\begin{array}{l}\text { Individual or } \\
\text { corporate }\end{array}$ & $\begin{array}{l}0=\text { Individual defendant only } \\
1=\text { Presence of corporate defendant }\end{array}$ & $\begin{array}{l}\text { Complaint, indictment, } \\
\text { information }\end{array}$ \\
\hline
\end{tabular}

Evidence

characteristics

\begin{tabular}{lll}
\hline Witness evidence & $\begin{array}{l}0=\text { No witnesses } \\
1=\text { Witness evidence }\end{array}$ & $\begin{array}{l}\text { Exhibits, judgment, appeal } \\
\text { opinion, docket }\end{array}$ \\
\hline
\end{tabular}




\begin{tabular}{lll}
\hline Forensic evidence & $\begin{array}{l}0=\text { Qualitative evidence presented only } \\
1=\text { Quantitative evidence presented }\end{array}$ & $\begin{array}{l}\text { Exhibits, judgment, appeal } \\
\text { opinion, docket }\end{array}$ \\
\hline Additional evidence & $\begin{array}{l}0=\text { Information in charging document } \\
\text { is only evidence filed } \\
1=\text { Additional evidence filed }\end{array}$ & $\begin{array}{l}\text { Exhibits, judgment, appeal } \\
\text { opinion, docket }\end{array}$ \\
& \\
\hline
\end{tabular}


Table II. All case results

\begin{tabular}{|c|c|c|}
\hline Variable & Frequency & Percentage \\
\hline \multicolumn{3}{|l|}{ Dependent } \\
\hline \multicolumn{3}{|l|}{ Disposition } \\
\hline Voluntary dismissal & 1 & $3 \%$ \\
\hline Settlement & 9 & $24 \%$ \\
\hline Jury trial & 3 & $8 \%$ \\
\hline Bench trial & 1 & $3 \%$ \\
\hline Default/summary judgment & 8 & $22 \%$ \\
\hline Guilty plea & 15 & $41 \%$ \\
\hline \multicolumn{3}{|l|}{ Independent } \\
\hline \multirow{2}{*}{\multicolumn{3}{|c|}{ Case characteristics }} \\
\hline & & \\
\hline One count & 5 & $14 \%$ \\
\hline Two to five counts & 24 & $65 \%$ \\
\hline Six to ten counts & 5 & $14 \%$ \\
\hline Eleven or more counts & 3 & $8 \%$ \\
\hline \multicolumn{3}{|l|}{ Cryptocurrency } \\
\hline Other coin only or unspecified & 11 & $30 \%$ \\
\hline Bitcoin involved & 26 & $70 \%$ \\
\hline \multicolumn{3}{|l|}{ Defendant characteristics } \\
\hline \multicolumn{3}{|l|}{ Number of defendants } \\
\hline One defendant & 13 & $35 \%$ \\
\hline Two to five defendants & 22 & $60 \%$ \\
\hline Six or more defendants & 2 & $5 \%$ \\
\hline \multicolumn{3}{|l|}{ Type of defendants } \\
\hline Individual defendant only & 19 & $51 \%$ \\
\hline Presence of corporate defendant & 18 & $49 \%$ \\
\hline \multicolumn{3}{|l|}{ Evidentiary characteristics } \\
\hline \multicolumn{3}{|l|}{ Witness evidence } \\
\hline No witness & 22 & $60 \%$ \\
\hline Witness evidence & 15 & $41 \%$ \\
\hline \multicolumn{3}{|l|}{ Forensic evidence } \\
\hline Qualitative evidence presented only & 24 & $65 \%$ \\
\hline Quantitative evidence presented & 13 & $35 \%$ \\
\hline \multicolumn{3}{|l|}{ Additional evidence } \\
\hline Information in charging document is only evidence filed & 19 & $51 \%$ \\
\hline Additional evidence filed & 18 & $49 \%$ \\
\hline
\end{tabular}




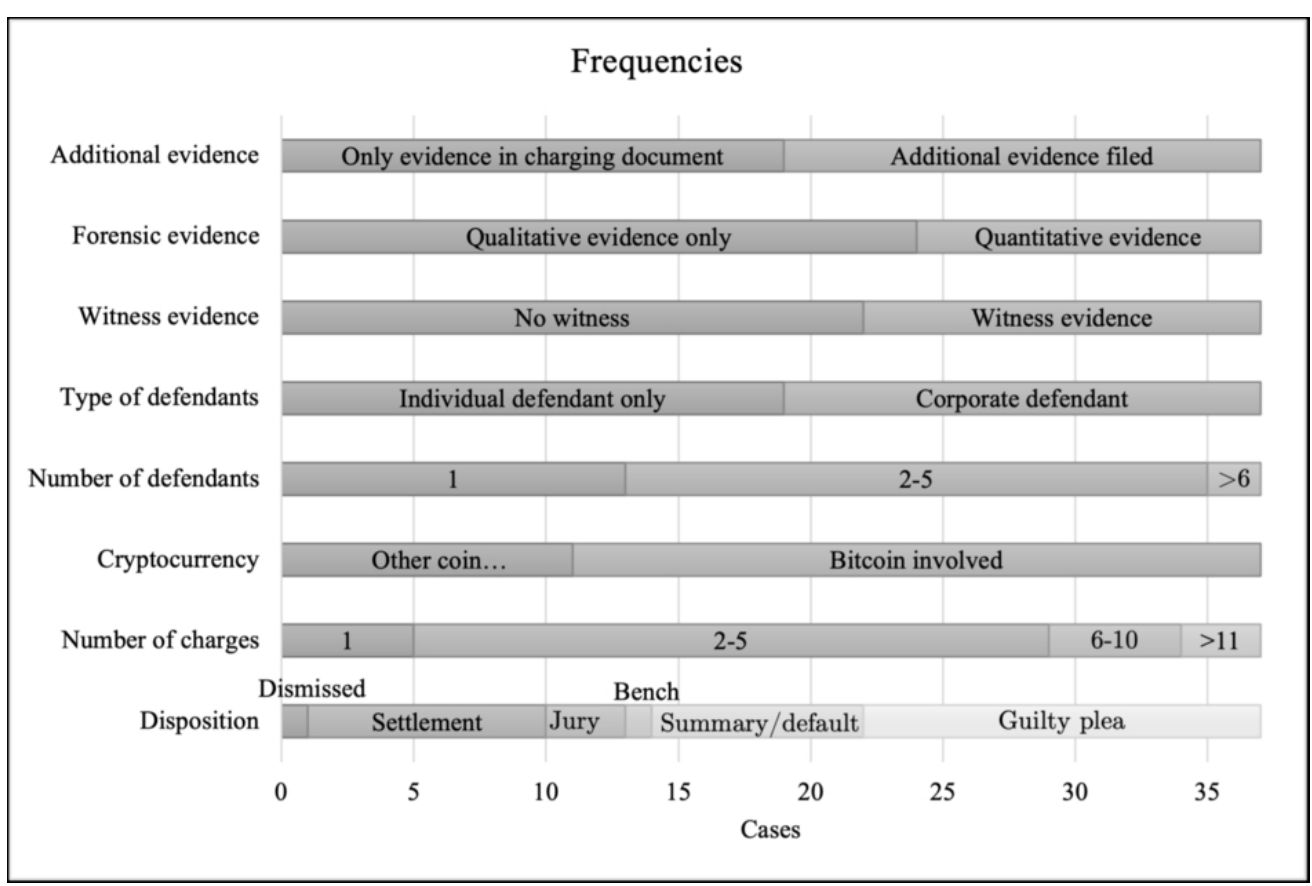

All case results $160 \times 106 \mathrm{~mm}(150 \times 150$ DPI $)$ 
Table III. Effect of independent variables on disposition: aggregated disposition (resolved by guilty plea or settlement or resolved by other means) and number of defendants (one or more than one)

\begin{tabular}{lllll}
\hline Disposition & & $\begin{array}{l}\text { Standard } \\
\text { Error }\end{array}$ & Significance & $\begin{array}{c}\text { Odds } \\
\text { ratio }\end{array}$ \\
& & 2.080 & .096 & \\
\hline Dismissal, & Intercept & 2.371 & .912 & .769 \\
trial, or & One count charged & 1.818 & .867 & .737 \\
summary or & 2-5 counts charged & 1.887 & .221 & 10.081 \\
default & 6-10 counts charged & 1.801 & .030 & .020 \\
judgment & Bitcoin not used & 1.418 & .770 & 1.514 \\
& One defendant & 1.833 & .019 & .014 \\
& Individual defendant only & .409 & .213 \\
& Qualitative evidence only & 1.875 & .434 & .252 \\
\hline
\end{tabular}

